\title{
The study on Dorsal Venous Arch of Upper Limb Among Nepalese Medical Students at Tertiary Level Teaching Institute
}

\author{
Nripendra Tiwari, Deepesh Budhathoki and Krishna Banshi Malla
}

Department of Anatomy, Kathmandu Medical College Teaching Hospital, Sinamangal, Kathmandu

\begin{abstract}
Introduction: Dorsal venous arch of upper limb is the beginning site for cephalic and basilic veins. The superficial veins are clinically important for venipuncture, blood collection and blood donation as well as for health screening and testing, intravenous transfusion for the emergency treatment of hypovolemic shock. Veins of the upper limb are also used for total parental nutrition, therapeutic invasive procedure and blood samples. The Dorsal Venous Arch is superficially placed and can be easily made prominent by putting a tourniquet at the wrist for any such surgical and therapeutic purposes.

Methods: It was a cross-sectional observational study conducted in 200 hands among 100 individuals from MBBS first and second year students studying at a Medical College. Body Mass Index (BMI) of individuals was calculated to observe the correlation between length of the dorsal venous arch and BMI.

Results: The mean \pm s.d. length of dorsal venous arch in male on right hand $(20.7 \pm 2.4 \mathrm{~cm})$ was significantly greater than in female on right hand $(19.4 \pm 2.1 \mathrm{~cm})$. There was no significant difference in length of dorsal venous arch on left side between male $(20.1 \pm 2.2 \mathrm{~cm}$.) and female $(19.3 \pm 1.8 \mathrm{~cm})$.

Conclusions: The length of the dorsal venous arch on right hand was found significantly greater in male than in female. Also the length of dorsal venous arch on right side was found to be more than on left side in both sexes. The male students are significantly older, heavier and taller than females.

Key words: basilic vein; cephalic vein; dorsal venous arch.
\end{abstract}

Correspondence: Nripendra Tiwari, Department of Anatomy. Kathmandu Medical College Teaching Hospital, Sinamangal,Kathmandu, Nepal. Email: nriti2000@gmail.com

DOI: http://dx.doi.org/10.3126/mjsbh.v18i2.21216

Submitted on: $2018-10-01$

Accepted on: 2019-01-16

This work is licensed under creative common license:

http://creativecommons.org/licenses/by-nc-nd/4.0/ (C) MJSBH 2019 


\section{INTRODUCTION}

Dorsal venous arch or network of upper limb is the beginning site for cephalic on lateral side and basilic veins on medial side of forearm. ${ }^{1}$ The cephalic and basilic veins, which are the superficially placed veins, are clinically important for venipuncture, blood donation, blood collection and intravenous transfusion in emergency treatment of hypovolumic shock. ${ }^{2}$ Blood sampling, blood transfusion and intravenous injections are also commonly performed at cubital fossa of upper limb for which median cubital vein is the vein of choice. ${ }^{3}$ However, equal importance nowadays is given for locating cephalic vein at anatomical snuff box, the origination for which is the dorsal venous arch. ${ }^{4}$ Cephalic vein at radial styloid process is the invariable content of anatomical snuff box is good candidate for venous access. ${ }^{5,6}$ Anatomical snuff box is the important bony landmark and thus the vein is used for a large number of invasive and surgical procedures especially in case for syncope and obese patients, where other superficial veins of upper limb are difficult to locate them. ${ }^{7,8}$ The clinician must have the sound knowledge of the common sites at which these superficial veins like cephalic and basilic veins are found with its different variations in order to expose them. ${ }^{9}$ These superficial veins are meant for transfusing blood to a patient in state of shock when the other veins are in collapsed state and therefore invisible. ${ }^{10}$ The total length of dorsal venous arch is measured over the arch from styloid process of radius to styloid process of ulna by adding length of fifth vein on medial aspect, length of thumb vein on lateral aspect and length of dorsal digital vein of middle three fingers. ${ }^{11}$ Thus the aim of the present study is to access the dorsal venous arch of the upper limb among Nepalese preclinical students at a Medical College.

\section{METHODS}

The study was conducted at a tertiary level teaching institute in Kathmandu, Nepal from July 2017 to December 2017 after receiving the ethical clearance from Institutional Review Committee. A cross-sectional observational study of dorsal venous arch was conducted in 200 hands among 100 Nepalese medical students (100 hands in 50 males, 100 hands in 50 females) from MBBS first and second year students. Interested volunteers, who gave the written consent and age group between 18 to 25 years of age were included in the study. Data was collected from respondents by a self designed questionnaire in a written form to obtain the necessary socio demographic information on age and sex. Foreign students studying at our institute and individuals who did not give consent in written form were excluded from the research work. Individuals participating in the research work were asked to wash their hands, with liquid soap provided by the department. Tourniquet was placed about $3 \mathrm{~cm}$. proximal or above the anterior distal crease of the wrist. A photograph of each hand with dorsal venous arch was recorded. Immediately the arch was coloured with temporary blue sketch pen and then again photographed. Length of the dorsal venous arch was measured from styloid process of radius to styloid process of ulna of the same hand of an individual. The total length of dorsal venous arch was calculated by adding length of fifth vein on medial aspect of hand, length of thumb vein on lateral aspect of hand and length of dorsal digital vein of middle three fingers in anatomical position. The measured length of thread on dorsal venous arch was then transferred into unit of centimetre in metallic scale recorded into structured proforma. Tourniquet was removed subsequently from the hand being observed. Same procedure was performed to the other hand of the same individual. 10 to 15 individuals were observed at a time in leisure period of students. Photograph was observed in detail and was recorded in structured proforma. Data collected was compiled in Microsoft Office Excel 2007 and further analysed by SPSS version 20. Mean and standard deviation were calculated. The independent t-test was used to compare the significant difference between two means between the study variables. $p$ value $<0.05$ was considered as statistically significant. 
Table 1. Results of length of dorsal venous arch and BMI of preclinical students $(\mathrm{N}=200$ hands)

\begin{tabular}{|c|c|c|c|c|c|c|}
\hline \multirow{2}{*}{$\begin{array}{l}\text { Demographic } \\
\text { Data }\end{array}$} & \multicolumn{2}{|c|}{ Mean } & \multicolumn{2}{|c|}{ Standard Deviation } & \multirow[t]{2}{*}{ t-statistics } & \multirow[t]{2}{*}{ p-value } \\
\hline & Male & Female & Male & Female & & \\
\hline Age (yrs) & 19.8 & 19.1 & 1.2 & 1.6 & 2.70 & 0.008 \\
\hline Weight (kg) & 63.1 & 52.3 & 10.7 & 7.9 & 5.76 & 0.000 \\
\hline Height (cm) & 171.4 & 159.4 & 6.3 & 5.3 & 10.386 & 0.000 \\
\hline BMI $\left(\mathrm{kg} / \mathrm{m}^{2}\right)$ & 21.5 & 20.6 & 3.6 & 2.8 & 1.41 & 0.162 \\
\hline $\begin{array}{l}\text { Length of right dorsal venous } \\
\text { arch in } \mathrm{cm}\end{array}$ & 20.7 & 19.4 & 2.4 & 2.1 & 2.938 & 0.004 \\
\hline $\begin{array}{l}\text { Length of left dorsal venous } \\
\text { arch in } \mathrm{cm}\end{array}$ & 20.1 & 19.3 & 2.2 & 1.8 & 1.897 & 0.061 \\
\hline
\end{tabular}

\section{RESULTS}

The mean \pm s.d. length of dorsal venous arch in male on right hand $(20.7 \pm 2.4 \mathrm{~cm})$ was significantly greater than in female $(19.4 \pm 2.1 \mathrm{~cm})$. There was no significant difference in length of dorsal venous arch on left side between male (20.1 $\pm 2.2 \mathrm{~cm})$ and female $(19.3 \pm 1.8 \mathrm{~cm})$. The length of dorsal venous arch on right side was found to be slightly greater than the left side in both sexes (Table 1). The mean \pm s.d age of male students was $19.8 \pm 1.2$ years and that for female was $19.1 \pm 1.6$ years. The mean \pm s.d weight of male students was $63.1 \pm 10.7 \mathrm{~kg}$ and that for female was $52.3 \pm 7.9$ $\mathrm{kg}$. Also the mean $\pm \mathrm{s}$.d height of male students was $171.4 \pm 6.3 \mathrm{~cm}$. and that for female was $159.4 \pm 5.3$ $\mathrm{cm}$. The mean \pm s.d BMI for male students was $21.5 \pm 3.6 \mathrm{~kg} / \mathrm{m}^{2}$ and that for female was $20.6 \pm 2.8$ $\mathrm{kg} / \mathrm{m}^{2}$. This showed that the male students were

Table 2. Results of correlation matrix of BMI and length of right dorsal venous arch and length of left

\begin{tabular}{|c|c|c|c|}
\hline Variables & $\begin{array}{l}\text { Body } \\
\text { Mass } \\
\text { Index } \\
\text { (BMI) }\end{array}$ & $\begin{array}{l}\text { Length of } \\
\text { Right } \\
\text { Dorsal } \\
\text { Venous } \\
\text { Arch }\end{array}$ & $\begin{array}{l}\text { Length of } \\
\text { left Dorsal } \\
\text { Venous } \\
\text { Arch }\end{array}$ \\
\hline $\begin{array}{l}\text { Body Mass } \\
\text { Index }\end{array}$ & 1 & $\begin{array}{l}-0.087 \\
(0.391)\end{array}$ & $\begin{array}{l}-0.117 \\
(0.248)\end{array}$ \\
\hline $\begin{array}{l}\text { Length of Right } \\
\text { Dorsal Venous } \\
\text { Arch }\end{array}$ & & 1 & $\begin{array}{c}0.588 \\
(0.000)\end{array}$ \\
\hline $\begin{array}{l}\text { Length of Left } \\
\text { Dorsal Venous } \\
\text { Arch }\end{array}$ & & & 1 \\
\hline
\end{tabular}

significantly older, heavier and taller than females. The result on BMI showed no significant difference in male and female. $12 \%$ (6) of males and 10\% (5) of females were overweight and 6\% (3) of males and $2 \%$ (1) of females were found to be obese. The condition for overweight and obesity are in increasing trend among Nepalese medical students. We found significant correlation between length of right dorsal venous arch and length of left dorsal venous arch. However, there was no statistical correlation found between body mass index and length of dorsal venous arch among preclinical students (Table 2).

\section{DISCUSSION}

The investigations in the present study revealed that dorsal venous arch vary from person to person and in the same individual on both right and left sides.

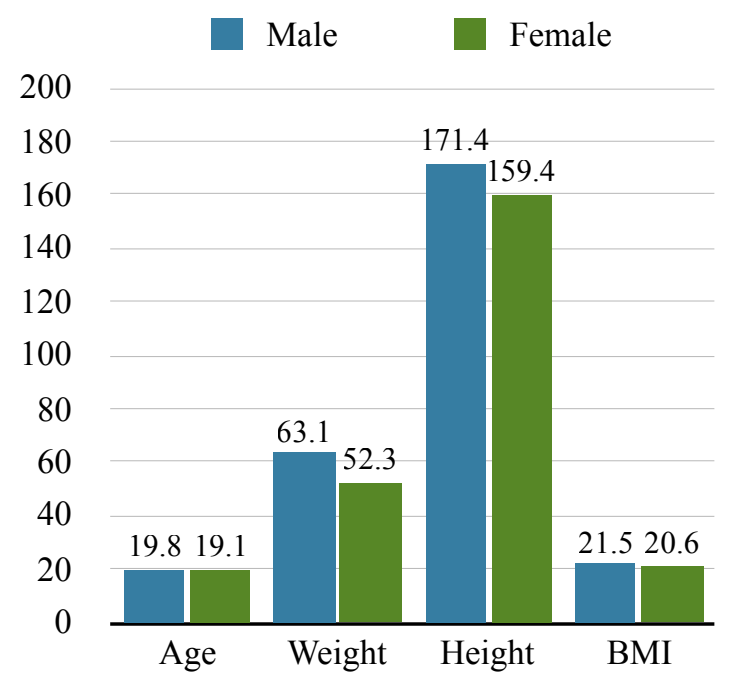

Figure 1. Distribution of mean age, mean weight, mean height and mean BMI in male and female 


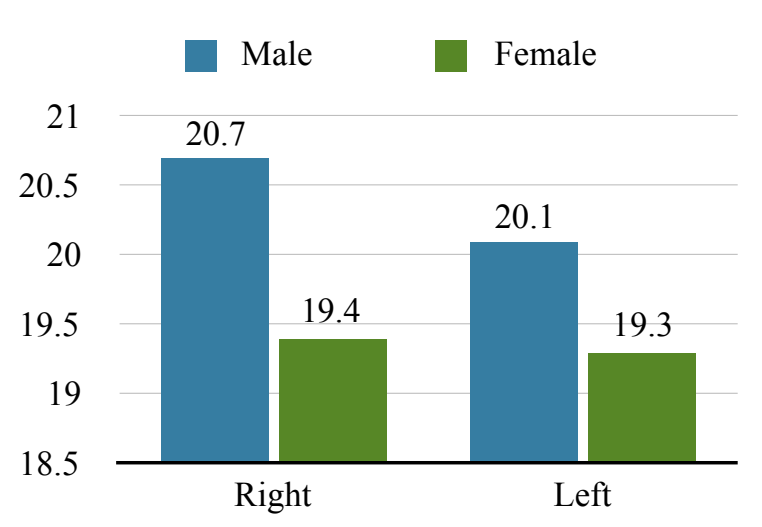

Figure 2. Distribution of length of dorsal venous arch (in $\mathrm{cm}$ ) in males and females

Our result showed that the length of dorsal venous arch in male was greater than in female preclinical students among 200 hands in 100 students sample representative of the college. The investigations in the present study revealed the mean length of the dorsal venous arch on right side as $20.7 \mathrm{~cm}$ and on left side as $20.1 \mathrm{~cm}$ in male and $19.4 \mathrm{~cm}$ on right side and $19.3 \mathrm{~cm}$ on left side in female. Similar results of dorsal venous arch found were published in the year 2012 researched by Taneja, Younus and Howale. ${ }^{11}$ They found the length of dorsal venous arch in range of 9.5 to $20 \mathrm{~cm}$. on right hand and 10.2 to $17.7 \mathrm{~cm}$ on left hand. They also found the greater length of dorsal venous arch on right hand than on left hand. Our result showed slight difference in length of dorsal venous arch. The cause for difference could be due to racial, social, ethnical background and dominant hand of the sample size. The age group considered in their study was between 25 to 50 years. However the consideration for age group in our study was between 18 to 25 years. The mean age of male students in our study was 19.8 years and that for female was 19.1 years. The mean BMI for male students was $21.5 \mathrm{~kg} / \mathrm{m}^{2}$ and that for females was $20.6 \mathrm{~kg} / \mathrm{m}^{2} .12 \%$ (6) of males and $10 \%$ (5) of females were overweight and 6\% (3) of males and $2 \%$ (1) of females were found to be obese. One of the research conducted by Nafiu O, Burke C, Cowan A, Tremper K in year $2009^{12}$ studied the relationship between BMI and ease of venous access in children with belief that obesity is widely associated with difficult peripheral intravenous access placement and they found that obese children were more likely to require two or more attempts at cannulation than lean children. Another research done by Rezende MS et al. in year $2017^{13}$ found association between upper limb volume and venous blood flow velocity in upper limb. We found no correlation between the length of dorsal venous arch of hand and the body mass index. The lack of correlation in our result could be due to the sample size and non-invasive procedure adopted for our study.

\section{CONCLUSIONS}

The length of the dorsal venous arch for male was found to be more than female. Also the length of dorsal venous arch on right side was found to be more than on left side in both sexes. The condition for overweight and obesity are in increasing trend among preclinical Nepalese students. Awareness about weight, height and BMI are still inadequate even among medical students. There was no statistical correlation found between the length of dorsal venous arch and the body mass index.

\section{LIMITATIONS}

As we have adopted the non-invasive procedure to measure the length of dorsal venous arch of hand for safety and comfort in living subjects, we were unable to observe the external and internal circumference, diameter and thickness of the veins. Therefore the fine dissection of the cadavers is necessary to find out the detail of dorsal venous arch in future.

\section{ACKNOWLEDGEMENTS}

I would like to acknowledge all the medical students of the College who participated in the study and the supporting staffs of Department of Anatomy who cooperated in the research work. 
To cite this article: Tiwari N, Budhathoki D, Malla KB. The study on dorsal venous arch of upper limb among nepalese medical students at tertiary level teaching institute. MJSBH. 2019;18(2):48-52.

Conflict of Interest: None declared

\section{REFERENCES}

1. Povoski SP. A prospective analysis of the cephalic vein cutdown approach for chronic indwelling central venous access in 100 consecutive cancer patients. Ann Surg Oncol. 2000;7:496-02.

DOI: https://doi.org/10.1007/s10434-000-0496-9

2. Horattas MC, Wright DJ, Fenton AH. Changing concepts of deep venous thrombosis of the upper extremity: report of a series and review of the literature, Surgery. 1988;104:561-67.

DOI: https://doi.org/10.1097/01.blo.0000181146.78434.da

3. Sukop A, Tvrdek M, Kufa R. Clinical anatomy of dorsal venous network in fingers with regard to replantation. Clin Anat. 2006;20(1):77-81.

DOI: https://doi.org/10.1002/ca.20287

4. Iimura A, Nakamura Y, Itoh M. Anatomical study of distribution of valves of the cutaneous veins of adult's limbs. Ann Ana.t 2003;185:91-5.

DOI: https://doi.org/10.1016/s0940-9602(03)80019-5

5. Bazan HA, Schanzer H. Transposition of the brachial vein: a new source for the autologous arteriovenous fistula. $\mathbf{J}$ Vasc Surg. 2004;40:184-6.

DOI: https://doi.org/10.1016/j.jvs.2004.03.044

6. Kim KH, Byun EJ, Hyun E. Ultrasonic findings of superficial radial nerve and cephalic vein. Ann Rehabil Med. 2014;38(1):52-6.

DOI: https://doi.org/10.5535/arm.2014.38.1.52

7. Hillock GG. Macrovascular surgery and the microsurgeon. J Reconstr Microsurg. 1997;13:563-70.

DOI: https://doi.org/10.1055/s-2007-1006438

8. Mandel SR, Martin PL, Blumoff RL, Mattern WD. Vascular access in a university transplant and dialysis program: Results, costs and manpower implications. Arch Surg. 1977;112:1375-80.

DOI: https://doi.org/10.1001/archsurg.1977.01370110109012

9. Winsett OE, Wolma FJ. Complications of vascular access for the hemodialysis. South Med J. 1985;78:513-7. DOI: https://doi.org/10.1097/00007611-198505000-00004

10. Singh SP, Ekandem Gj, Bose S. A study of the superficial veins of the cubital fossa in Nigerian subjects. Acta. Anat. 1982;114:317-20.

DOI: https://doi.org/10.1159/000145603

11. Taneja C,Younus M, Howale DS. The study of dorsal venous arch of hand in living adult males in Udaipur District of Rajasthan. Int. Journal of Current Research and Review. 2012;04(05):89-92.

12. Nafiu O, Burke C, Cowan A, Tremper K. Comparing peripheral venous access between obese and normal weight children. Paed. Anaes. 2010;20(2):172-6.

DOI: https://doi.org/10.1111/j.1460-9592.2009.03198.x

13. Rezende MS, Marsengo AL, Apolinario A, Ferreira VTK. Correlation between upper limb volume and arterial and venous blood flow velocity in lymphedema secondary to breast cancer treatment. J Manipulative Physiol Ther. 2017;40(4):241-5.

DOI: https://doi.org/10.1016/j.jmpt.2017.02.008 